\title{
Innovative cervical splint: overcoming an obstacle
}

\author{
Saurabh Gupta, Ravi Kumar Chittoria, Elankumar Subbarao, Konda Sireesha Reddy, Vinayak Chavan, \\ Abhinav Aggarwal, Chirra Likhitha Reddy
}

Department of Plastic Surgery, Jawaharlal Institute of Postgraduate Medical Education and Research, Pondicherry 605006, India.

Correspondence to: Dr. Ravi Kumar Chittoria, Department of Plastic Surgery, Jawaharlal Institute of Postgraduate Medical Education and Research, Pondicherry 605006, India. E-mail: drchittoria@yahoo.com

How to cite this article: Gupta S, Chittoria RK, Subbarao E, Reddy KS, Chavan V, Aggarwal A, Reddy CL. Innovative cervical splint: overcoming an obstacle. Plast Aesthet Res 2018;5:46. http://dx.doi.org/10.20517/2347-9264.2018.66

Received: 13 Sep 2018 First Decision: 2 Dec 2018 Revised: 6 Dec 2018 Accepted: 13 Dec 2018 Published: 26 Dec 2018

Science Editor: Raúl González-García Copy Editor: Cui Yu Production Editor: Huan-Liang Wu

\begin{abstract}
Cervical splints are used to maintain the neck position in burn patients with involvement of neck, which provides pain relief and prevent hypertrophic scarring and contracture. Due to the technical difficulty, cervical splinting often deferred in patients with tracheostomy. To overcome the difficulty the authors have described a simple modification of hard cervical collar, which provided adequate immobilization and adequate space for tracheostomy care. Innovative modification of hard cervical collar proposed in this case report can be a solution to overcome the difficulty posed by tracheostomy in patients sustained with neck burns.
\end{abstract}

Keywords: Modified cervical splint, neck burns, tracheostomy, cervical collar

\section{INTRODUCTION}

Partial and full-thickness burns in neck region are reported in $35 \%$ of total burn patients ${ }^{[1]}$. Neck burns are associated with inhalational injuries and airway edema; and it is necessary to secure the airway early in these cases either by endotracheal intubation or tracheostomy. The majority of these patients present with airway edema, tracheostomy is preferred over endotracheal intubation in view of difficult airway.

Serghiou et al. ${ }^{[2]}$ has quoted that "The position of comfort is the position of deformity". Hence physical rehabilitation of patients who have sustained burn injury is an important part of management and requires multimodality treatment which involves splinting of affected part. In patients of neck burns, neck needs to be maintained in 15 degree extension ${ }^{[2]}$. Tracheostomy tube acts as an obstacle for applying neck splint ${ }^{[3]}$. We present a simple modification of hard cervical collar to be used in tracheostomized patients.

cc) (i) (C) The Author(s) 2018. Open Access This article is licensed under a Creative Commons Attribution 4.0 (c) The Author(s) 2018. Open Access This article is licensed under a Creative Commons Attribution 4.0
International License (https://creativecommons.org/licenses/by/4.0/), which permits unrestricted use, sharing, adaptation, distribution and reproduction in any medium or format, for any purpose, even commercially, as long as you give appropriate credit to the original author(s) and the source, provide a link to the Creative Commons license, and indicate if changes were made.

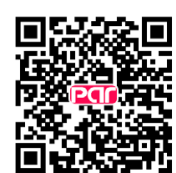




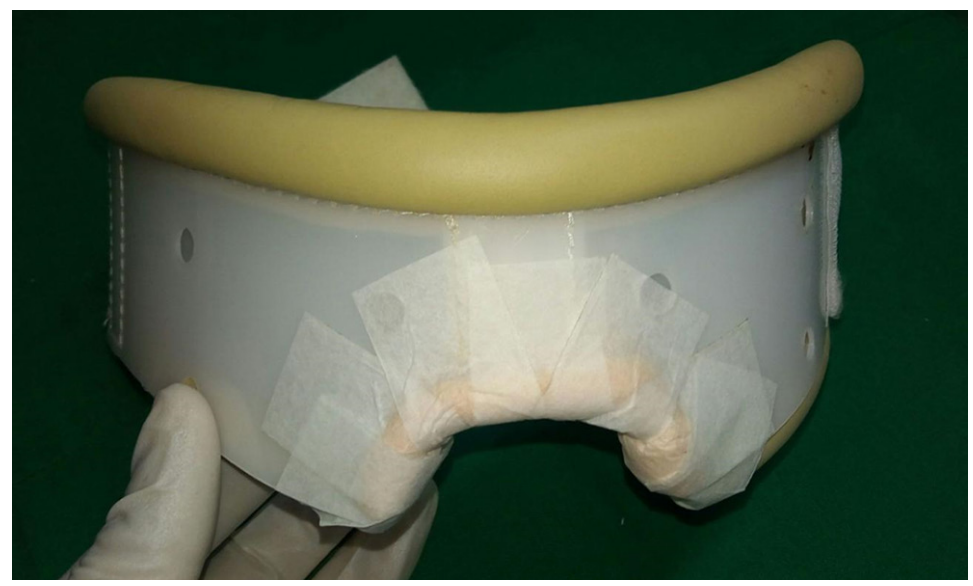

Figure 1. The modified neck splint

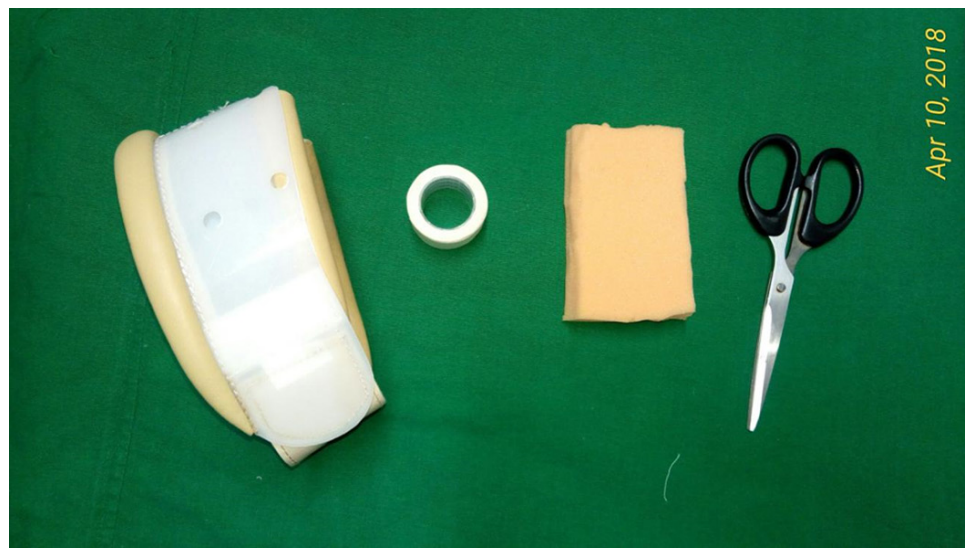

Figure 2. Materials required

\section{METHOD AND MATERIALS}

We present a case of a 23-year-old female presented to casualty with history of accidental flame thermal burn involving face, neck, chest and upper limbs constituting $25 \%$ of total body surface area with inhalational injury. Patient had stridor suggesting airway compromise, on attempted endotracheal intubation, severe upper airway edema was noted with non visualization of vocal chords so the patient was tracheostomized and was resuscitated as per Parkland formula. Hard cervical collar commonly applied to immobilize neck couldn't be fitted with tracheostomy tube in situ. To overcome this problem modification of hard cervical collar was designed [Figure 1].

We used medium size hard cervical collar (cost: INR300; USD5; Dynamic Techno Medicals Pvt. Ltd.) made up of poly vinyl chloride (PVC) [Figure 2]. The lower part of cervical collar was cut with stout scissors in a shape of inverted " $U$ " in its central part. While cutting the collar all the sharp projections were removed to make margins rounded. A clean piece of foam was cut into the half doughnut shape and fixed on the margins with the help of micropore tape [Figure 3]. After this modification collar was fit into the neck, providing pressure and positioning to the neck and simultaneously allowing rotational mobility for physiotherapy. Base of modified collar was stable from lateral sides [Figure 4]. Design map for modified neck splint is shown in Figure 5.

Modified cervical splint served the purpose of providing immobilization and alleviating pain during acute phase. Patient was well compliant to continuous application of modified cervical splint. Nursing caregivers 


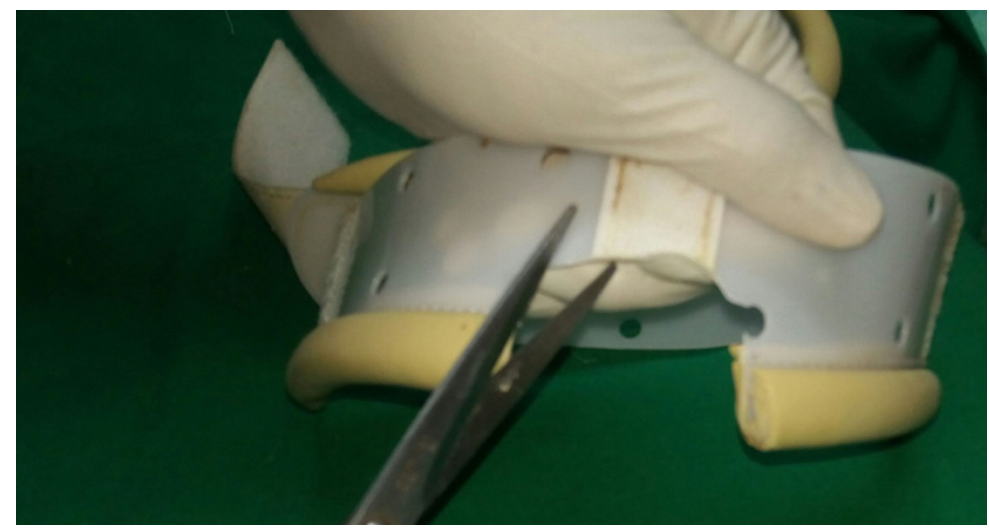

Figure 3. Preparing the modified neck splint

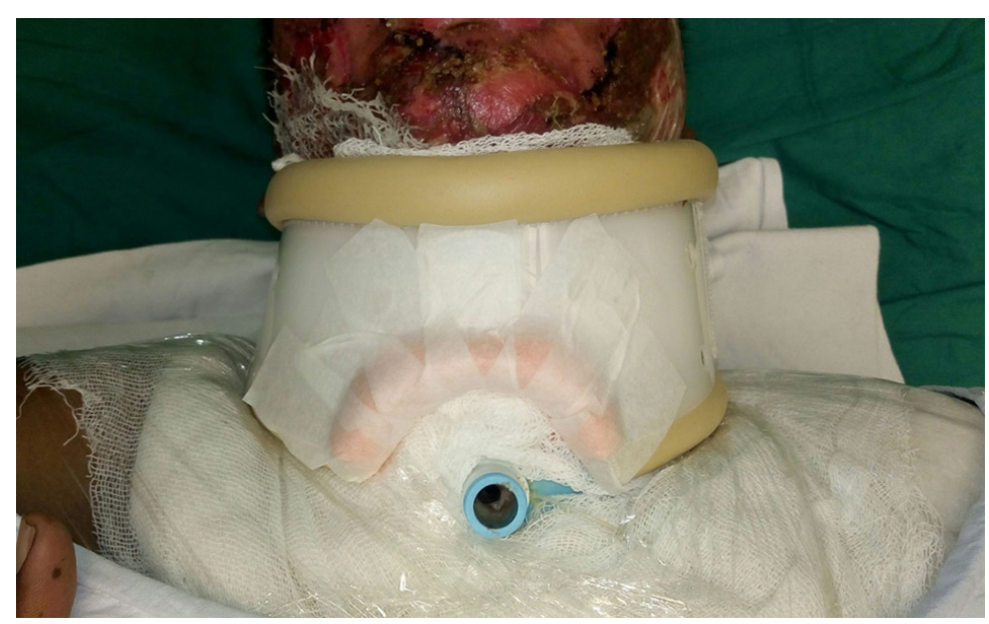

Figure 4. Patient wearing modified neck collar

were able to provide tracheostomy care easily with the modified cervical splint in situ. During recovery phase wounds were managed with regular hydrojet debridement, low level laser therapy, autologous platelet rich plasma therapy, insulin therapy and regulated oxygenation and negative pressure wound therapy. Once the wound bed became healthy autologous split skin graft was applied [Figure 6]. Patient responded well to the treatment and neck wounds are healing well. Graft take is adequate and there is no restriction in range of motion of neck [Figure 7]. Once the edema settled, planned weaning from the tracheostomy and decanulation has been done during recovery phase. Modified neck splint was applied after tracheostomy removal also. At present the patient is following same neck splint and having no complaint of discomfort.

\section{DISCUSSION}

Cronin was the first to report that post-burn contractures could be prevented with the application of a splint for prolonged pressure ${ }^{[4]}$. Commonly used splinting devises for neck are: (1) customized (patient specific; fabricated with fiberglas or thermoplastic material); and (2) prefabricated (with PVC or silicone or aliplast).

Traditionally, splinting with conforming thermoplastic collars have been utilized for anterior neck burns. However, the cost of thermoplastic material is high. Patient compliance with prefabricated neck collars is good. Prefabricated neck collars are easier to apply, readily available and cost effective. Prefabricated cervical splint can be hard or soft neck collars. Hard collar is made up of PVC while softer materials are aliplast or silicone lined elastic wraps. Prefabricated neck collars are available in different sizes (small, medium or 

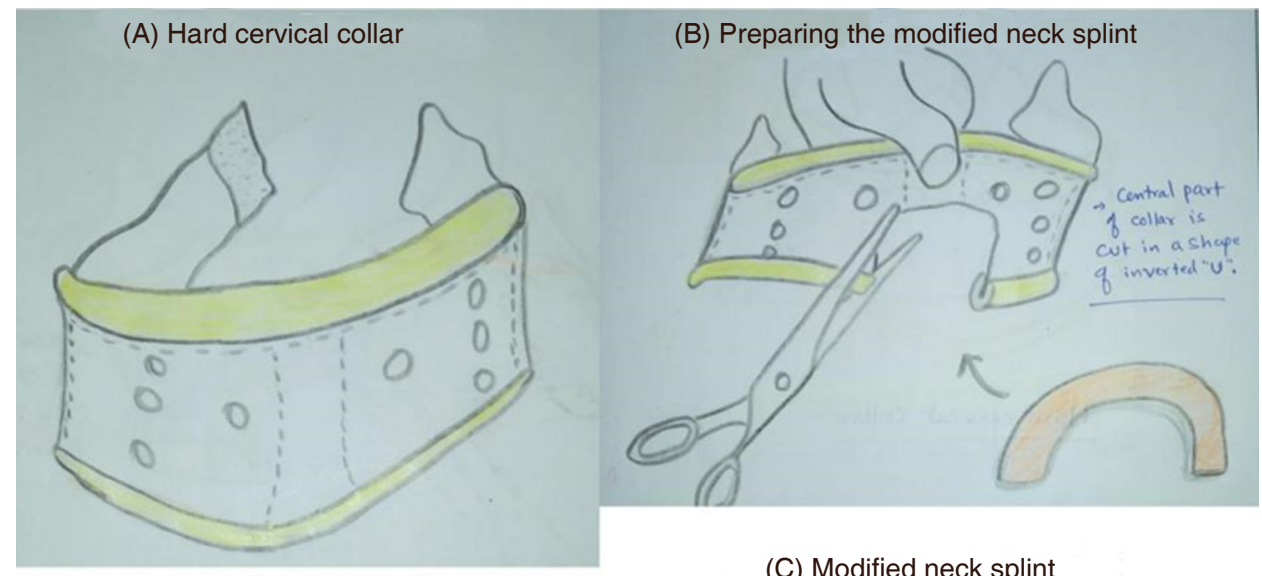

- Central part of the collar is cut

(C) Modified neck splint in a shape of inverted "U"

- Half doughnut shaped foam is cut and prepared

- Foam is fixed to the cut edge of the collar with the help of micropore tape

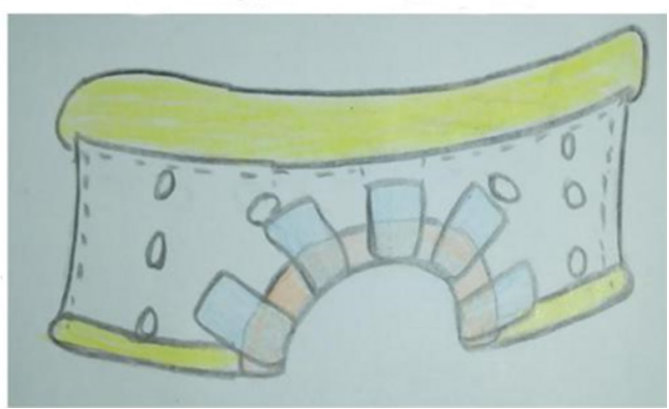

Figure 5. Design map for modified neck splint. A: Hard cervical collar; B: preparing the modified neck splint; C: modified neck splint

large). Hard cervical collars are better for burn patients as compared to soft cervical collar because of ease of application over bulky dressing and ease of cleaning the collar stained with soakage from the wounds $\mathrm{s}^{[5-8]}$.

In some burn patients it is necessary to secure the airway early (at the time of presentation). Indications of early tracheal intubation mainly include ${ }^{[9]}$ : (1) overt signs and symptoms of airway obstruction; (2) extensive burns to the head and neck; (3) inability to protect airway from aspiration; (4) significant toxicity from carbon monoxide or cyanide; (5) respiratory failure; (6) extensive burns (> 40\% of total body surface area); and (7) hemodynamic instability. In selected patients tracheostomy is preferred over translaryngeal route for tracheal intubation. Indications of tracheostomy in burn patients mainly include ${ }^{[9]}$ : (1) need for prolonged mechanical ventilation; (2) burns that will require multiple anesthesia for surgical procedures; and (3) extensive laryngeal oedema making translaryngeal intubation difficult. Tracheostomy tube should be removed once the need for prolonged or repeated intubation is over.

Putting cervical splint in patients with tracheostomy is difficult and often deferred. This has a negative effect on outcome and increases the need for neck reconstruction in future ${ }^{[3]}$. Modified prefabricated neck collars are designed for tracheostomized patients but they are costlier and not readily available in market. Philadelphia collar is having socket for tracheostomy but it is designed for cervical trauma and not for burns patients. Philadelphia collar does not give freedom of lateral rotational movement of neck.

Our modification of hard cervical collar is very simple and easy to adapt at any burn care centre. It is low cost, light weight, well supported, provides appropriate position and pressure, allows for physiotherapy and comfortable. We observed good compliance and pain relief in the patient to which modified neck splint was applied. It was possible to provide routine tracheostomy care comfortably with the patient wearing the modified neck splint. We look forward to use this modified neck splint in other neck burn patients with tracheostomy from the first day. 


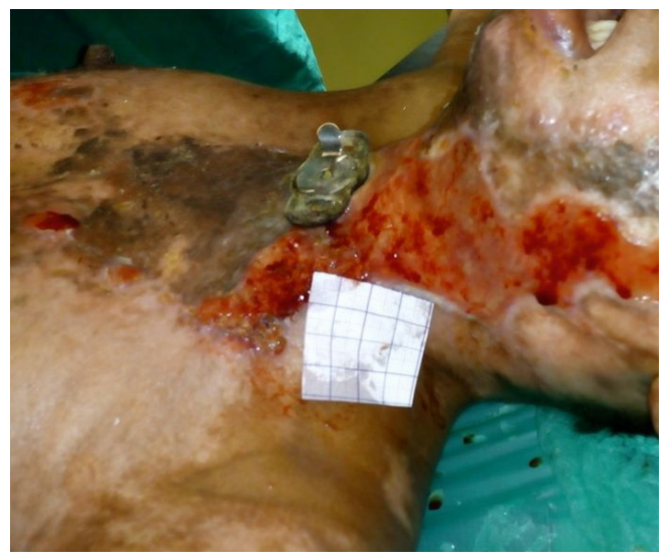

Figure 6. Burn wounds of the patient during treatment course; poly vinyl chloride tracheostomy tube is replaced with metallic tube

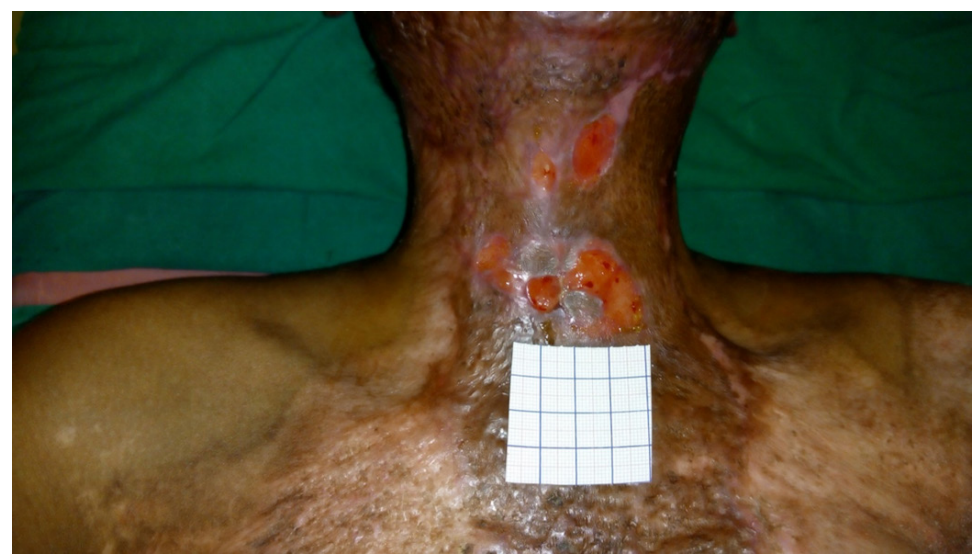

Figure 7. Small remaining wounds; tracheostomy tube is removed

\section{CONCLUSION}

Cervical splinting in neck burn patients with tracheostomy is necessary but difficult. The innovative modification of hard cervical collar proposed in our case report can be a solution to overcome this difficulty.

\section{DECLARATIONS}

\section{Authors' contributions}

Concept and design: Gupta S, Chittoria RK

Data acquisition and analysis, manuscript preparation: Gupta S, Aggarwal A

Critical revision and finalizing of the manuscript: Chittoria RK, Subbarao E, Reddy KS, Chavan V, Aggarwal A, Reddy CL

\section{Availability of data and materials}

The data were strictly obtained from medical records according to the privacy policy and ethics code of our institute.

\section{Financial support and sponsorship}

Jawaharlal Institute of Postgraduate Medical Education and Research.

\section{Conflicts of interest}

All authors declared that there are no conflicts of interest. 


\section{Ethical approval and consent to participate}

Due consent was taken from the patient to participate in the study and separately for the photography. Ethical approval was done according to the hospital and department policy.

\section{Consent for publication}

Written informed consent for publication was obtained.

\section{Copyright}

(c) The Author(s) 2018.

\section{REFERENCES}

1. Jaiswal AK, Aggarwal H, Solanki P, Lubana PS, Mathur RK, et al. Epidemiological and socio-cultural study of burn patients in MY Hospital, Indore, India. Indian J Plast Surg 2007;40:158-63.

2. Serghiou MA, Ott S, Whitehead C, Cowan A, McEntire S, et al. Comprehensive rehabilitation of the burn patient. In: Herndon DN, editor. Total burn care. Edinburgh: Elsevier; 2012. pp. 517-49.

3. Sharp PA, Dougherty ME, Kagan RJ. The effect of positioning devices and pressure therapy on outcome after full-thickness burns of the neck. J Burn Care Research 2007;28:451-9.

4. Cronin TD. The use of a molded splint to prevent contracture after split skin grafting of the neck. Probl Sovrem Neirokhirurgii 1961;27:718.

5. Richard R, Johnson RM, Miller SF. A compendium of customized burn splint designs. J Burn Care Rehabil 2003;24:S143.

6. Daugherty MB, Carr-Collins J. Splinting techniques for the burn patient. In: Richard RL, Staley MJ, editors. Burn care and rehabilitation: principles and practice. Philadelphia: FA Davis; 1994. pp. 250-3.

7. Jordan RB, Daher J, Wasil K. Splints and scar management for acute and reconstructive burn care. Clin Plast Surg 2000;27:71-85.

8. Hurlin Foley K, Doyle B, Paradise P, Parry I, Palmieri T, et al. Use of an improved watusi collar to manage pediatric neck burn contractures. J Burn Care Rehabil 2002;23:221-6.

9. Woodson LC, Talon M, Traber DL, Herndon DN. Diagnosis and treatment of inhalation injury. In: Herndon DN, editor. Total burn care. Edinburgh: Elsevier; 2012. pp. 232-36. 